\section{The effect of size, retinal locus, and orientation on the visibility of a single afterimage*}

\author{
JANETTE ATKINSON+ \\ The Psychological Laboratory, University of Cambridge, Cambridge, England
}

Unitary and fragmentary visibilities of the afterimage of a small rectangular bar were measured at three retinal loci. Unitary visibility was higher for foveal than for parafoveal viewing, whereas fragmentation was greater the longer the bar. A model for estimating the size of receptors has been applied and gives the mean size of a "functional unit" to be $1.5 \mathrm{deg}$ in the fovea and 3-4 deg parafoveally. Unitary visibility has been shown to be higher for vertical and horizontal bars than for obliquely oriented bars. Explanations for this result have been suggested in terms of the distribution, size, and selectivity of cortical orientation selective units.

Stabilized images undergo irregular but nonrandom fluctuations in their visibility (Riggs, Ratliff, Cornsweet, \& Cornsweet, 1953; Ditchburn \& Fender, 1955; Pritchard, Heron, \& Hebb, 1960 ; Evans, 1965). Examination of these fluctuations has led to the general conclusion that regeneration of the entire image, or some specifiable part of it, cannot be entirely explained in terms of lens slippage (Ditchburn \& Fender, 1955; Byford, 1962; Barlow, 1963; Riggs \& Schick, 1968). Certain structured disappearances and reappearances occur without any apparent changes in retinal input, and may represent the activity of perceptual units within the visual cortex.

In the study described here, the visibility of a stabilized image in the form of an afterimage of a single rectangular bar was measured as a function of stimulus size, locus, and orientation. The first experiment is an extension of an earlier one by Evans $(1966,1967)$, in which he deduces the size of receptive fields within the visual system from the properties of "functional units." A "functional unit" is considered as a cluster of cells with synchronous firing, so that if a stabilized vertical line is projected onto one of these units, it will tend to appear as a whole. Also, when it disappears, it will do so as a unit and not in fragments. A line which is longer than the functional unit will not be linked for synchronous firing

*This work was supported by a Science Research Council scholarship and the George Henry Lewes Studentship (Physiological Laboratory, Cambridge. England). The author wishes to thank Dr. 0 . J. Braddick. Dr. F. W. Campbell, and Dr. L. A. Riggs for their helpful criticisms of the manuscript.

tAddress: Physiolorical Laboratory, University of Cambridge, Downing St., Cambridge, England. and will be likely to appear and disappear in fragments. As image size approaches unit size, the probability of fragmentary appearances rises and unitary appearances decreases. An attempt is made in the present study to interpret the visibility and fragmentation of an afterimage in terms of functional unit size, using the above model.

\section{METHOD}

The afterimages were produced by a Braun F800 electronic flashgun. The flash duration was approximately $4 \mathrm{msec}$ as calibrated by displaying a photocell output on an oscilloscope. The light output, according to the manufacturer's specification, was $160 \mathrm{~J}$. A diffusion filter was placed in front of the flash tube. The flash was given in a room dimly illuminated at approximately 0.3 nits. Patterns were produced by cutouts in a black mask, placed in front of the diffusion filter.

\section{Subjects}

All Ss were students at the University of Cambridge; they were between 17 and 30 years of age and were naive as to the purpose of the experiments. All had normal or corrected to normal vision.

\section{Procedure}

The $\mathbf{S}$ fixated, with his right eye, a white spot attached to the mask. His left eye was covered throughout the trial by an eyepatch. His eyes were $28.5 \mathrm{~cm}$ from the flash and horizontally aligned with the fixation spot. Immediately after the flash, the $S$ closed his eyes and kept them closed throughout the trial time, thus maintaining a constant background luminance for viewing the afterimage.

The trial time was always $60 \mathrm{sec}$ immediately following the flash. The $S$ always had 15 -min adaptation before
Apparatus the first experimental trial and 5-min adaptation between trials. Afterimages lasted on average for $2-3 \mathrm{~min}$, although only the first minute of recording was analyzed. Certain artifactual factors, known to affect visibility of afterimages, were kept as constant as possible. The $S$ was asked to avoid blinking during the trial, to keep his head still, and to make as few voluntary eye movements as possible.

The S used small, two-way switches to record the visibility of the afterimage. The switches were always depressed by $\mathbf{S}$ when he could see the image and released when the image disappeared. The switches controlled counters which were separated from $S$ by a screen to prevent observation of the results during testing. Visibility was measured in seconds of trial time for which the afterimage was visible, as recorded on the counters at the end of each trial.

Orders of presentation were used which balanced for practice effects between different stimuli and viewing conditions.

\section{Experiment 1}

To establish the afterimage, the $\mathbf{S}$ fixated the center of the target (foveal condition) or 2 or $7 \mathrm{deg}$ to the right. Four different lengths of bar were used: $45 \mathrm{~min}, 1,2$, and $3 \mathrm{deg}$. Ten Ss completed three trials on each of the 12 viewing conditions. The first trial in each condition was treated as a practice trial, and the mean of the other two trials was used in the results. Two and a half sessions, each of $2 \mathrm{~h}$ duration, were required to complete the test trials for each $\mathrm{S}$.

The $S$ used two switches on each trial; he depressed the right-hand switch whenever the afterimage of the entire bar was visible (U) and the left-hand switch whenever anything was visible, either the whole bar or fragments of it $(U+F)$. The mean for the visibility of the bar as a unit, in fragments, and in either form were calculated for each $S$ on each condition.

\section{Experiment 2}

The total unitary visibility (U) of the afterimage of a single bar $1.5 \mathrm{deg}$ in length was measured for seven different orientations of the bar between 0 deg vertical and $90 \mathrm{deg}$ horizontal in 15-deg steps. Two Ss were tested with foveal viewing and three Ss tested using parafoveal viewing, $2 \mathrm{deg}$ to the right of fixation.

\section{RESULTS}

Experiment 1

Mean visibility is plotted as a function of the image for the three measures calculated (U, F, and $U+F$ ) in Fig. 1. An analysis of variance was 

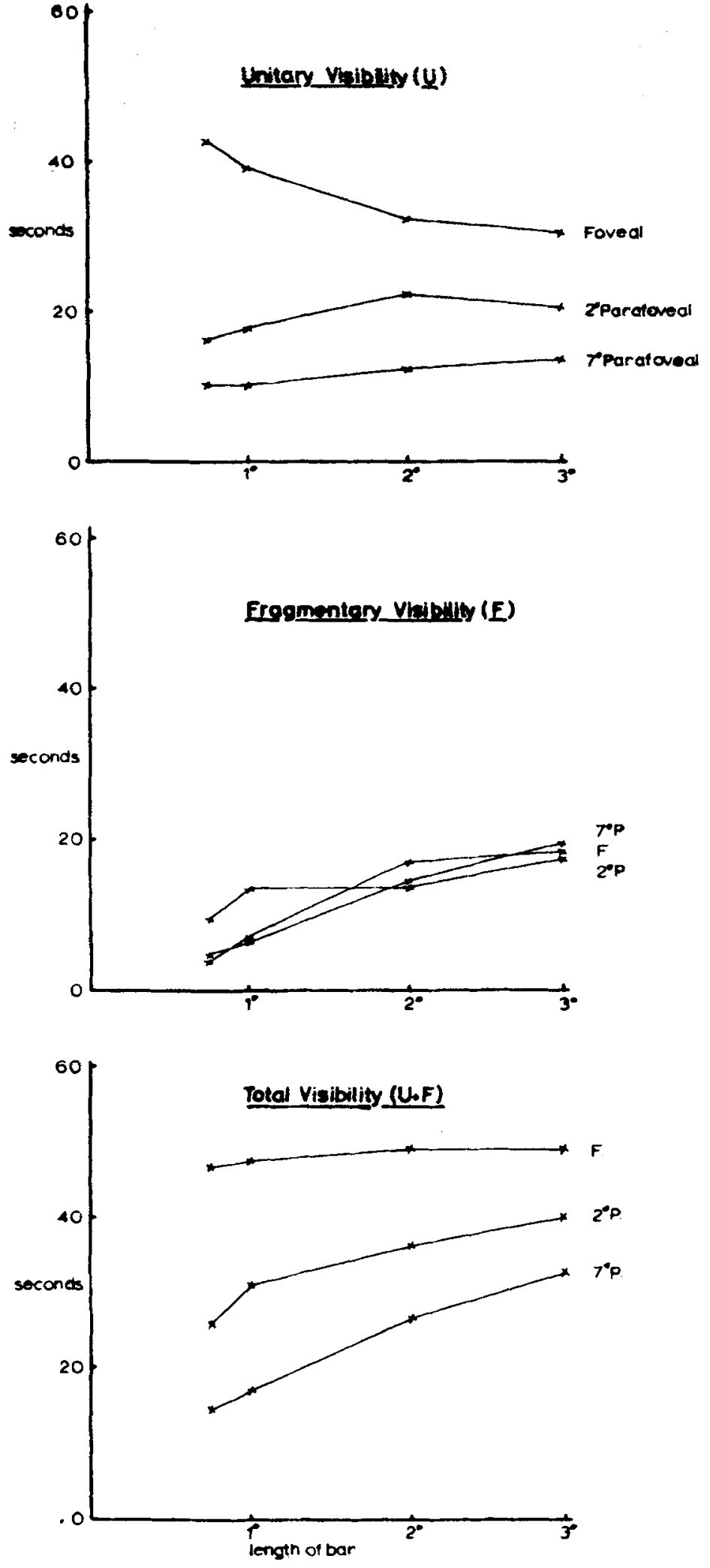

Fig. 1. Visibility (in seconds) as a function of bar length (in degrees) and retinal locus (in degrees from the central fovea). carried out on the results.

For the afterimage as a unit (U), there was a decline in visibility with increase in eccentricity $[F(2,18)=$ $48.5, p<.01]$. There was also an Eccentricity by Length of the Bar interaction $[F(6,54)=14.3, p<.01]$. For foveal viewing, the small bars appeared as a unit for more of the time than did long bars. For parafoveal viewing, unitary visibility was lower for small bars than for longer ones. For all three loci, fragmentation was increased by increase in length.

\section{Experiment 2}

A graph of unitary visibility as a function of orientation is shown in Fig. 2. An analysis of variance revealed a significant difference between different orientations of the bar $[F(6,6)=12.3, p<.01$, for foveal and $F(6,12)=6.4, p<.01$, for parafoveal viewing]. Comparison of the means for each orientation using the Newman-Keuls test (see Winer, 1962) revealed a significant difference between visibility of $a$ bar at 0 and 30 deg and between 90 and $60 \mathrm{deg}$, but no significant difference between 30,60 , and 45 deg.

The effect was small but slightly larger for foveal than for parafoveal viewing.

\section{DISCUSSION}

Experiment 1

In order to compare the results of Experiment 1 with those of Evans (1967), the means for the three measures were converted into the two scores used by him and are shown in Fig. 3. These were the disappearance of the bar as a unit (which is equal to trial time with the time anything is visible subtracted from it) and the disappearance of the bar in fragments (F).

Evans suggested a model to explain his results in which he predicts that as image size is increased, the probability of fragmentary disappearances rises and unitary disappearances decreases.

If line length is $X$ and the unit length, $L$, if it is assumed that all units are the same size and do not overlap, and if it is assumed that $X$ is smaller than $L$, then the expected number of boundaries that $\mathrm{X}$ will cross will be $X / L$. If the unit is inactive for fraction $f$ of trial time and two units are never inactive at the same time, then fragmentation time $=f X / L$ and the time of complete unitary disappearance $=f(1-X / L)$. When these two functions are equal, $\mathrm{X}=0.5 \mathrm{~L}$.

Using this model, the point at which the curve representing unitary disappearance crosses that representing fragmentary disappearance will indicate the size of the functional unit 
that is involved. This point is shown on the graphs in Fig. 3. Evans ansumes that the extimated size for functional units also indicates the size of receptive fields used in perception of the bars. Thus, from the results of Experiment 1, the foveal receptive field size would be 1.5 deg and the parafoveal 3 or 4 deg. These size estimates are much larger than those found by Evans.

There are two main differences between the two experiments-one is the difference in response made by the $S$ in each study and the other is the brightness of the flash used-but neither of these factors would be expected to give such large discrepancies between results. Only four Ss were tested by Evans, and large variabiltiy among Ss was noticed. Different receptive field sizes for different $\mathrm{Ss}_{8}$ would have to be postulated to fit his results, which would not be likely for such a basic neurophysiological property as receptive field size. The differences are probably due to differences in criteria used by different Ss in judging appearances and disappearances.

It seems likely that at least one of the assumptions that has to be made to accept Evans's model is not correct, namely, that functional units do not overlap. If there is overlap, then fragmentation time cannot be accurately specified without knowing the amount of overlap.

The differences in visibility recorded for foveal and parafoveal images suggest that the pattern detectors involved have somewhat different properties, particularly involving their functional size. There is a great deal of evidence from other studies to suggest that the size of units changes with shift in retinal locus. Hillman (1958) and Hallet (1963) measured the relationship between stimulus size and threshold luminance within the retina. They found that there was an increase in summation area with increase in eccentricity. It is well established that in man, acuity falls monotonically with increasing eccentricity of the stimulus (see Dor, 1873; Burchardt, 1893). Histological studies of the human retina have revealed a decreasing density of rods, cones, and bipolar and ganglion cells with increase in eccentricity (Vilter, 1949). What is more, anatomical evidence from Osterberg (1935) and Weymouth (1958) show that foveal and parafoveal units differ in density and dimensions. It is not surprising that visibility of the afterimage varies with eccentricity, but the precise location of the units determining these effects remains unresolved.

\section{Experiment 2}

There is an extensive literature on
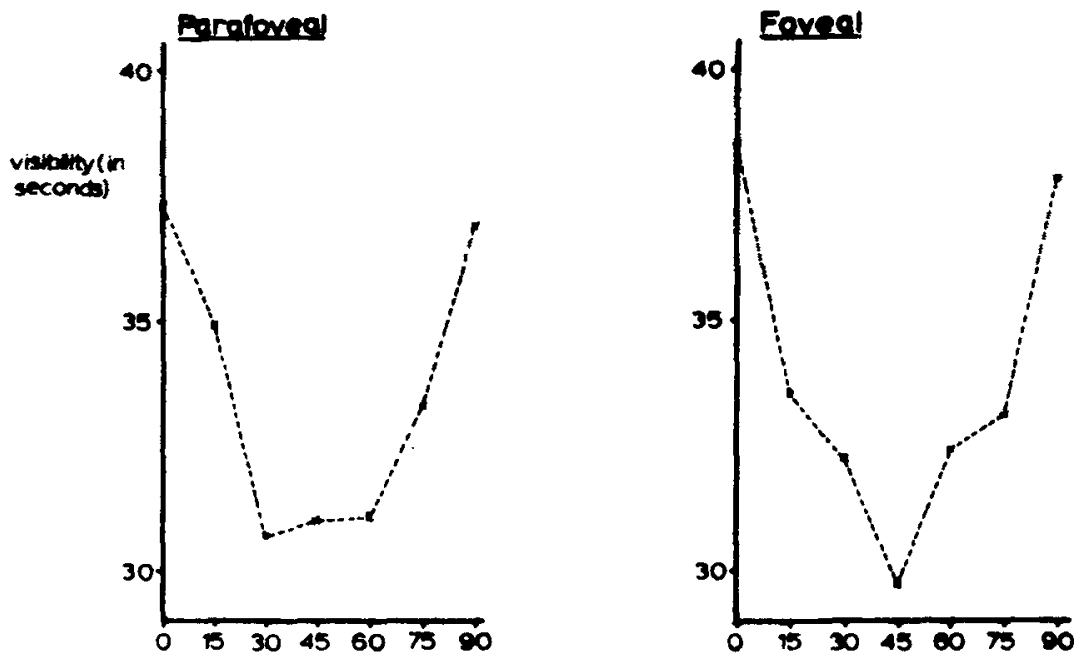

orientation (in degrees)

Fig. 2. Unitary visibility (in seconds) as a function of orientation (in degrees). 0 des indicates a vertical orientation.

meridional variations in slant perception. Emsley (1925), Leibowitz (1955), Ogilvie and Taylor (1958), Campbell, Kulikowski, and Levinson (1966), and Mitchell, Freeman, and Westheimer (1967) have all measured meridional variation in acuity and concluded that the threshold was higher for a 45-deg line than for one that was horizontally or vertically oriented. Campbell's study eliminated dioptrics as the possible cause of the variation. Jastrow (1892), Gibson and Radner (1937), Muller, Sidorsky, Slivinske, Alluisi, and Fitts (1955), Andrews (1967a,b), and Bouma and Andriessen (1968) have all measured the accuracy of absolute settings of a line to a particular orientation. Accuracy was found to be higher at the vertical and horizontal than at intermediate orientations. Recent masking experiments (Campbell \& Kulikowski, 1968; Houlihan \& Sekuler, 1968; Gilinsky, 1968) and measurements of the evoked potential also support the hypothesis that discrimination is finer at vertical and horizontal orientations than at $\mathbf{4 5} \mathrm{deg}$.

A study similar to the present experiment was carried out by Craig and Lichenstein (1953), who examined the disappearance of steadily fixated lines as a function of the orientation of the lines. Minima in the curve relating frequency of disappearance to orientation of the lines were found at the vertical and horizontal, with maxima at $45 \mathrm{deg}$. The authors concluded that perhaps the components of nystagmus were maximal in the direction of fewest disappearances. This explanation seems unsatisfactory in the light of the present experimental results on stabilized images.
Two neurophysiological models would meet the requirements of the psychophysical results. The first one proposes that detectors for vertical and horizontal lines are more numerous than detectors for other orientations, all detectors being of equal sensitivity. The alternative hypothesis assumes an even distribution of line detectors, but with those sensitive to vertical and horizontal orientations having a narrower bandwidth (higher selectivity) than those tuned to oblique orientations.

Campbell, Cleland, Cooper, and Enroth-Cugell (1968), looking at the distribution of orientation-selective units in cat visual system, did not find any difference between the number selective to oblique orientations and those to vertical or horizontal orientations. Hubel and Wiesel (1962, 1965,1968 ) also found no asymmetry in the distribution for cat and monkey visual cortical units. However, in any microelectrode study, as the number of units sampled is small compared to the total number of orientation units present, it would be quite possible for the expected real, but small, unevenness in the distribution to be obscured.

The effects found in the present study have been measured in terms of increase or decrease in unitary visibility of an afterimage, which is a somewhat different measure from that used in other psychophysical or physiological studies. If it is assumed that higher visibility reflects the simultaneous firing of a larger number of cells or single units forming a functional unit, then the findings here would reflect an asymmetrical distribution of receptors. In contrast, if 


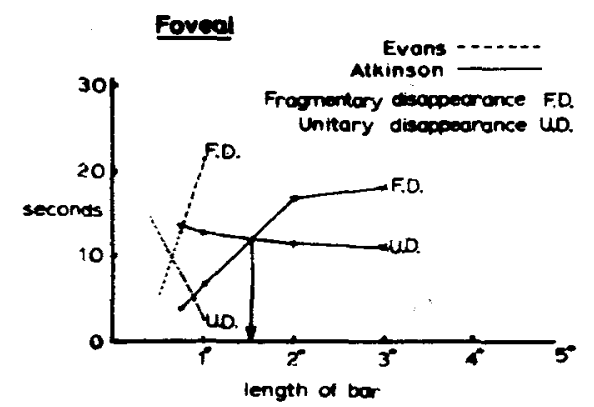

2. Ponotorel

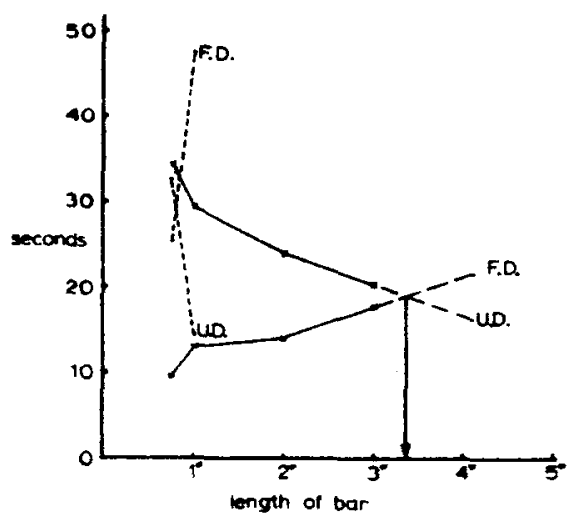

T Poratoveal

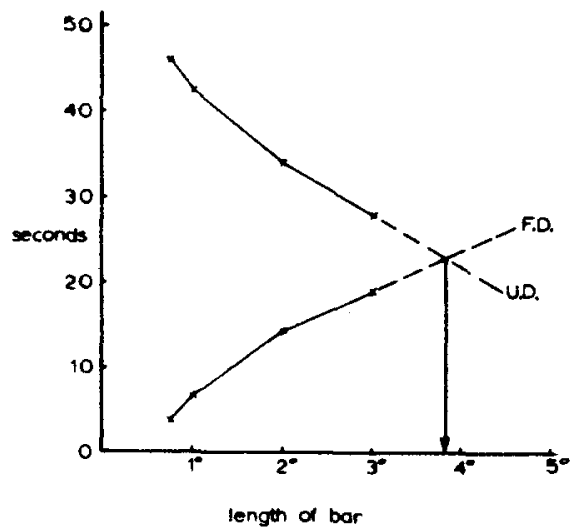

Fig. 3. Unitary and fragmentary disappearances (in seconds) as a function of bar length and retinal locus (in degrees).

the same assumption holds and the second hypothesis is correct (i.e., there is a difference in selectivity with orientation), then the total visibility for vertical and horizontal bars would be lower than for bars at oblique orientations. Where the bandwidth was narrow (near the vertical and horizontal), a given bar would fall within the bandwidth of fewer cells than where the bandwidth was wide (at $45 \mathrm{deg}$ ). At present, it is impossible to say whether the above assumption is true or not, and so no definite decision as to which hypothesis is correct can be made.

A third possible alternative explanation of the result, which can be tested in a future experiment, is that the difference in visibility noted for the various orientations reflects differences in the size of functional units; those sensitive to vertical and horizontal lines are larger than those sensitive to oblique lines. Unitary and fragmentary visibilities for different lengths at different orientations will be compared to test the hypothesis. The relative difference in functional unit size would necessarily be in the same direction at different eccentricities, for the meridional effect was found both at foveal and parafoveal viewing positions.

While the exact reason for the variation cannot as yet be decided, it is clear that the functional units responding must be highly sensitive to orientation and as such must be cortical, for units lower in the visual system do not show the same sensitivity to this feature.

\section{SUMMARY AND CONCLUSION}

The main conclusion from Experiment 1 is that the total visibility of an afterimage of a small rectangular bar is higher when the image is viewed foveally than when it is viewed parafoveally. As the length of the bar is increased, the amount of time the afterimage is seen in fragments is also increased. A difference has been suggested in the size of functional units detecting the afterimage for foveal and parafoveal viewing.

Experiment 2 has shown that total visibility of an afterimage also depends on the orientation of the bar. Horizontal and vertical bars are visible for longer than bars at intermediate orientations. Three possible explanations for this result have been put forward: asymmetry in the distribution of orientation-selective units, differences in bandwidth for units selective to different orientations, and differences in the size of units for different orientations. It is not possible in the light of these experimental results to decide among the three explanations.

\section{REFERENCES}

ANDREWS, D. P. Perception of contour orientation in the central fovea: I. Short lines. Vision Research, 1967a, 7 . 975-997.

ANDREWS, D. P. Perception of contour orientation in the central fovea: II. Spatial integration. Vision Research, $1967 \mathrm{~b}, 7,999-1013$.

BARLOW, H. P. Slippage of contact lenses and other artifacts in relation to fading and regeneration of supposediy stable retinal images. Quarterly Journal of Experimental Psychology, 1963, 15, 36-51.

BOUMA, H., \& ANDRIESSEN, J. J.
Perceived orientation of isolated line segments. Vision Research, 1968, 8, 493-507.

BURCHARDT, $L$. In $H$. von Helmholtz, Handbuch der physiologischen Optik. (Trans. J. C. Southall) Optical Society of America, 1925, II, 368.

BYFORD, G. H. The fidelity of contact lens eye movement recording. Optica Acta, $1962,9,223-236$.

CAMPBELL, F. W., CLELAND, B. G., COOPER, G. F., \& ENROTH-CUGELI, C. The angular selectivity of visual cortical units to moving gratings. Journal of Physiology, 1968, 198, 237-250.

CAMPBELL, F, W., \& KULIKOWSKI, J. J. Orientation selectivity of the human visual system. Journal of Physiology, $1966,187,437-445$.

CAMPBELL, F. W., KULIKOWSKI, J. J., \& LEVINSON, J. The effect of orientation on the visual resolution of gratings. Journal of Physiology, 1966, 187, 427-436.

CRAIG, E. A., \& LICHENSTEIN, M. Visibility-invisibility cycles as a function of stimulus orientation. American Journal of Psychology, 1953, 66, 554-563.

DITCHBURN, R. W. \& FENDER, D. H The stabilized retinal image. Optica Acta, 1955, 2, $128-133$.

DOR, $H$. In $H$. von Helmholtz, Handbuch der physiologischen Optik. (Trans. J. C. Southall) Optical Society of America, 1925, II, 368.

EMSLEY, H. H. Irregular astigmatism of the eye. Effect of correcting lenses. Transactions of the Optical Society. London, 1925, 27, 28-42.

EVANS, C. R. Some studies of pattern perception using a stabilized retinal image. British Joumal of Psychology, $1965,56,121-133$.

EVANS, C. R. A new approach to pattern perception. Discovery, 1966, 17, 17-21.

EVANS, C. R. Further studies of pattern perception and a stabilized retinal image: The use of prolonged afterimages to achieve perfect stabilization. British Journal of Psychology, 1967, 58, 315-327.

GIBSON, J. J., \& RADNER, M. Adaptation, aftereffect, and contrast in the perception of tilted lines: I. Quantitative studies. Journal of Experimental Psychology, $1937,20,453-467$.

GILINSKY, A. S. Orientation-specific effects of patterns of adapting light on visual acuity. Journal of the Optical Society of America, 1968, 58, $13-18$.

HALLETT, P. E. Spatial summation. Vision Research, 1963, 2, 9-25.

HILIMAN, C. Relationship between stimulus size and threshold intensity in the fovea measured at four exposure times. Journal of the Optical Society of America, 1958, 48, 422.

HOULIHAN, K., \& SEKULER, R. W. Contour interaction in visual masking Journal of Experimental Psychology, $1968,77,281-285$.

HUBEL, D. H., \& WIESEL, T. N. Receptive fields, binocular interaction and functional architecture in the cat's visual cortex. Journal of Physiology, 1962, 160 . 106-154.

HUBEL, D. H., \& WIESEL, T. N. Receptive fields and functional architecture in two nonstriate visual areas (18 and 19) of the cat. Journal of Neurophysiology, 1965 , 28, 229-289.

HUBEL, D. H., \& WIESEL, T. N. Receptive fields and functional architecture of monkey striate cortex. Journal of Physiology, 1968, 195, 215-243.

JASTROW, J. On the judgement of angles and positions of lines. American Joumal of Psychology, 1892, 8, 214-222.

LEIBOWITZ, H. W. Some factors influencing the variability of vernier acuity. American Journal of Psychology, $1955,68,266-273$.

MITCHELL, D. E., FREEMAN, R. W., \& 
WESTHEIMER, G. Effect of orientation on the modulation sensitivity for interference fringes on the retina. Journa of the Optical Society of America, 1967. 57. 246-249.

MULLER, P. F., SIDORSKY, R. C. SLIVINSKE, A. J., ALLUISI, E. A., \& FITTS, P. $M$. The symbolic coding of information on cathode tubes and similar displays. U.S. Air Force, WADC Technical Report No. 55-375, xi, 123.

OGILVIE, J. C., \& TAYLOR, M. M. Effect of orientation on the visibility of fine wires. Journal of the Optical Society of America, 1968, 48, 628-629.
OSTERBERG, G. Topography of the layer of rods and cones in the human retina. Acta Ophthalmologica, 1935, Suppl 6.

PRITCHARD, R. M., HERON, W., \& HEBB, D. O. Visual perception approached by the method of stabilized images. Canadian Journal of Psychology, 1960, 14, 67-77.

RIGGS, L. A. \& SCHICK, A. M. L. Accuracy of retinal image stabilization Accuracy of retinal image stabilization fitting contact lens. Vision Research, $1968,8,159-169$.

RIGGS, L. A., RATLIFF, F., CORNSWEET, J. c., \& CORNSWEET,
N. The disappearance of steadily fixated visual test objects. Journal of the Optical Society of America, 1953,43,495-501. VILTER, V. Reserches Biométriques sur l'organization synaptique de la retina humaine. Academie des Sciences, Paris, Comptes Rendus, 1949, 143, 830-832.

WEYMOUTH, F. W. Visual sensory units and the minimal angle of resolution. American Journal of Ophthalmology. $1958,46,102-113$

WINER, B. J. Statistical principles and experimental design. New York: McGraw-Hill, 1962.

(Accepted for publication March 27, 1972.) 